\title{
Perú: Diga a las usuarias cómo usar el método escogido
}

Frontiers in Reproductive Health

Follow this and additional works at: https://knowledgecommons.popcouncil.org/departments_sbsr-rh How does access to this work benefit you? Let us know!

\section{Recommended Citation}

"Perú: Diga a las usuarias cómo usar el método escogido," FRONTERAS Resúmenes de Investigación Operativa. Ciudad de México: Population Council, 2001. 


\section{Perú \\ Calidad de la atención}

\section{Resumen de 109}

\section{Diga a las usuarias cómo usar el método escogido}

\author{
Los prestadores de servicios de planificación familiar en el Perú \\ necesitan concentrarse más en dar a las usuarias la información \\ relevante sobre el método que eligieron y en hacer preguntas clave \\ para optimizar el tiempo de consejería.
}

\section{Antecedentes}

En 1998, el Ministerio de Salud (MS) peruano expidió normas de calidad de la atención para garantizar que los proveedores de planificación familiar respondieran adecuadamente a las necesidades y metas de salud reproductiva de sus clientas. A mediados de 1999, el Population Council colaboró con el MS para realizar un estudio de la calidad de atención. Este informe se concentra en un aspecto del estudio: determinar si la duración de las sesiones de consejería influía en la cantidad de información que la clienta recibía.

Utilizando la técnica de muestreo para la garantía de calidad por lotes, el estudio se realizó en 19 centros de salud de 10 áreas urbanas, seleccionados de una muestra nacional de 172 puntos de prestación de servicios. Durante junio y julio de 1999, seis clientas simuladas (mujeres que se hacían pasar por clientas) hicieron un total de 114 visitas a los 19 centros de salud. A cada clienta simulada se le entrenó para decir que deseaba cambiar el método del ritmo por un método más efectivo. Después de la consejería, estas clientas escogían el anticonceptivo inyectable DepoProvera, pero expresaban su deseo de hablar con su esposo antes de empezar a usarlo, y así podían abandonar el establecimiento sin recibir la inyección.

Para evaluar la calidad de la consejería, las clientas simuladas llenaban una lista de verificación después de cada visita, indicando la información que habían recibido. La lista de verificación contenía 46 items que representaban un intercambio óptimo de información. La lista cubría: preguntas para identificar factores relevantes de las opciones anticonceptivas; información sobre los métodos disponibles; preguntas para detectar contraindicaciones para el uso de inyectables; información sobre el uso de inyectables, efectos secundarios y signos de alarma; uso de métodos de barrera para protección temporal contra el embarazo, e instrucciones de seguimiento.

\section{Resultados}

Los proveedores dieron más información durante sesiones de nueve minutos o más que en sesiones más breves. Durante las sesiones de 9 a 14 minutos, los proveedores cubrían el 42 por ciento de los 46 puntos de la lista de verificación, comparado con el 30 por ciento que se cubría en sesiones de ocho minutos o

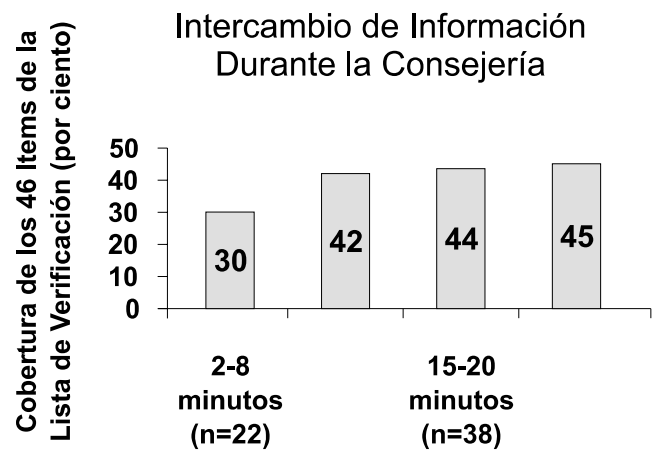


menos. Sin embargo, en sesiones de consejería de 15 a 45 minutos, el intercambio de información mejoró muy poco.

Las sesiones de consejería de mayor duración no mejoraron el intercambio de información porque los prestadores usaron el tiempo adicional para dar información sobre los métodos que las mujeres no usarían, en vez de darles información esencial sobre el método que habían elegido y de identificar las contraindicaciones para su uso. En menos del 20 por ciento de las visitas, los proveedores preguntaron sobre sangrado vaginal, hablaron del cáncer de mama, recomendaron el uso temporal de métodos de barrera o se aseguraron de que la clienta hubiera entendido la información recibida.

Sin embargo, los proveedores cumplieron con muchas de las metas de calidad de atención. En más de cuatro de cada cinco sesiones de consejería, los prestadores hicieron las preguntas estándar requeridas para evaluar las opciones anticonceptivas, hablaron de cuatro o más métodos anticonceptivos y pidieron a la clienta que seleccionara un método.

Los proveedores que participaron en el estudio recibieron con agrado la retroalimentación sobre la calidad de su consejería. Dijeron que no podían dar información más completa, debido principalmente a las limitaciones de tiempo. Algunas visitas fueron demasiado breves, pero la duración promedio fue de 15 minutos, tiempo suficiente para dar la información clave. La conclusión de los investigadores fue que los proveedores podrían haber usado más eficientemente el tiempo de consejería y habían perdido oportunidades para dar una atención más centrada en la usuaria al no hacer preguntas que determinaran su situación y necesidades particulares.

\section{Implicaciones normativas}

- El MS debe ensayar un modelo alternativo de consejería para ayudar a los proveedores a brindar una consejería en planificación familiar más efectiva y centrada en la clienta. Este modelo consta de cinco pasos:

1. Dar la bienvenida cordialmente;

2. Hacer un diagnóstico centrado en la clienta para identificar un subconjunto de métodos de planificación familiar adecuados;

3. Proporcionar información apropiada y personalizada sobre métodos adecuados para la clienta, con el fin de apoyarla en la selección de un método;

4. Detectar contraindicaciones; educar sobre el uso del método elegido y dar instrucciones para el seguimiento, y

5. Retroalimentar para asegurarse de que la información se entendió y de que habrá un seguimiento adecuado.

Este modelo debe hacer hincapié en el papel del proveedor después de que la mujer elige un método anticonceptivo, que incluye identificar contraindicaciones, dar instrucciones sobre el uso correcto del método, y hablar de sus efectos secundarios y de los signos de alarma. El MS debería desarrollar instrumentos de apoyo que ayuden a los prestadores a implantar este modelo y evaluarlos en investigaciones operativas.

Marzo 2001

León, Federico R. et al., 1999. Perú: Counseling Sessions Length and Amount of Information Exchange in Peruvian Clinics. Para obtener más información, escriba o llame a: Population Council-Oficina Regional para América Latina y el Caribe. Escondida 110 , Villa Coyoacán, 04000, México, D.F. México. Tel. (52)-55-54-03-88; Fax: (52)-55-54-12-26; E-mail: disemina@popcouncil.org.mx.

Este proyecto fue posible gracias al apoyo de la Agencia de los Estados Unidos para el Desarrollo Internacional (USAID) bajo el Acuerdo de Cooperación número HRN-A-00-98-00012-00. 